\title{
Workplace Diversity and Group Relations: An Overview
}

\author{
Julie Christian \\ University of Birmingham
}

Lyman W. Porter

University of California, Irvine

Graham Moffitt

University of Birmingham

\begin{abstract}
The study of conflict and diversity within groups, ranging from small workgroups to multinational organizations, has become an increasingly important focus for contemporary research. A key question is how the inevitable social diversity within groups can be developed as a productive asset rather than becoming a source of conflict and prejudice. The aim of this Special Issue of the journal is to report cutting edge empirical and theoretical work that addresses the broad issue of diversity and group-based conflict within workgroups. In this introduction, we briefly examine approaches that have been applied, and review what has been learned. We conclude by providing an overview to the Special Issue articles, highlighting central themes and implications for future research.
\end{abstract}

KEYWORDS diversity, intergroup relations, intragroup relations

\section{Introduction}

ONE of the most challenging issues facing organizations today is that of dealing with workgroup diversity. Recent legal, cultural, and demographic factors (e.g. globalization, multiculturalism, declining birth rates, equality initiatives) have changed the composition of organizations' work forces, such that they are more varied than in the past, and research suggests they will become even more diverse in the future (Jackson, 1992; Williams \& O'Reilly, 1998). For example, US labor force population estimates predict an increase of non-white workers from $16.5 \%$ in 2000 to $18.8 \%$ in 2010 , and further growth is expected, raising the minority workforce to $25 \%$ by 2050 (Fullerton \& Toossi, 2001). As a consequence of these changes and other shifts in industrial settings, employers, managers, and employees in organizations will be progressively required not only to be sensitive to intra- and intergroup

\section{Author's note}

Address correspondence to Julie Christian, School of Psychology, University of Birmingham, Edgbaston, Birmingham B15 2TT, UK [email: J.N.Christian@bham.ac.uk] 
differences, but also to adopt policies and practices that are effective in coping with such changes.

Recognizing the timeliness of the issues surrounding diversity research is not a difficult task. It is not just the topical nature of diversity management that signals its importance, even though research into the field of diversity management continues to be, arguably, one of the fastest growing areas of group processes and group relations research. In our view, the field began to make major advances at the point at which researchers changed their focus from simply noting that there was a relationship between group/individual differences and group performance, and began examining in depth the circumstances under which diversity can influence-and potentially improve-performance. This transition also marks a shift that helps chart the course for future research-a more important task than just answering questions about group similarities and differences. The following section, therefore, briefly considers various developments in defining and measuring diversity, but also links this to potential moderators and mediators of diversity on performance outcomes. We then turn our attention to applications of information processing and social identification/self categorization which have been widely applied in the literature, and which give us some of the strongest 'third variable' explanations of the effects of diversity on behaviour. Finally, we conclude with a brief discussion of the research presented within the Special Issue. It is worth noting, however, that while individual authors have drawn out study implications, framing them as representing either intra-group or inter-group dimensions, arguably diversity influences group dynamics more broadly. That is, diversity can be more strongly perceived as operating at an intra or inter-group level depending on the context applied. And so reflecting on the latter point-that perceived differences can be influential on many levels and even simultaneous-we have tailored our commentary to capture this view.

\section{Diversity, performance and cohesion}

Ely and Thomas (2001) noted that research on diversity has spanned the spectrum from examining diversity within the context of identitybased and organizational-based group memberships, such as race-ethnicity, gender, tenure, and function (e.g. Kanter, 1977; McLeod, Lobel, \& Cox, 1996; Pelled, Eisenhardt, \& Xin, 1999) through to more idiosyncratic characteristics such as political background, military experience and weight (Hickman \& Creighton-Zollar, 1998). The most commonly researched attributes, however, are age, gender, raceethnicity, functional background, educational background, and tenure (Jackson, Joshi, \& Erhardt, 2003; Milliken \& Martins, 1996; Williams \& O'Reilly, 1998). While there is general consensus among researchers as to what constitutes diversity management, there is little agreement on the effect that it has in the workplace. Given that this has been extensively debated elsewhere, we will not attempt to review all of the arguments here (for reviews see: Haslam, 2001; Jackson, Joshi \& Erhardt, 2003; Milliken \& Martins, 1996; Stewart, 2006; Webber \& Donahue, 2001; Williams \& O'Reilly, 1998).

A principal aim of diversity management research has been to increase our understanding of the effects that workgroup diversity has on cohesion and performance. During the past two decades, we can conclude that diversitymixed composition workgroups-can improve group performance by providing groups with a wider range of perspectives and a broader skills base, but simultaneously it can be detrimental to group cohesion and performance because the diversity in personal backgrounds has the potential to exert a negative influence (Milliken \& Martins, 1996). However, the literature is further complicated by the fact that when considering individual studies exploring the effects of diversity on performance and cohesion, researchers often report conflicting findings. Bantel (1994), for example, suggests that increased diversity results in better group performance. On the other hand, this is balanced against evidence that there is a 
negative relationship between diversity, cohesion, and performance, meaning that group cohesion, and performance increase as diversity decreases (Harrison, Price, \& Bell, 1998; Simons, Pelled, \& Smith, 1999; Wiersema \& Bantel, 1992). And, finally, Ancona and Caldwell (1992) and Smith et al. (1994) report a null relationship-that diversity and group cohesion have no relationship with performance.

In an attempt to better understand the effects of diversity on cohesion and group performance, many studies have attempted to classify diversity attributes. Such taxonomies have included readily detectable vs. less observable traits (e.g. Jehn, Northcraft, \& Neale, 1999; Millikens \& Martins, 1996; Tsui, Egan, \& O'Reilly, 1992; Van Knippenberg, De Dreu, \& Homan, 2004), surface-level vs. deep-level diversity (Phillips, Northcraft \& Neale, this issue) highly job-related vs. less job-related (Pelled, 1996; Pelled et al., 1999), task-related vs. relations-oriented (Jackson, May, \& Whitney, 1995) and role-related vs. inherent dimensions (Maznevski, 1994). These distinctions are largely a product of the two most common theoretical approaches in the diversity management literature, namely, the information/decision-making perspective (for reviews see, Williams \& O'Reilly, 1998) and the social categorization perspective (Tajfel \& Turner, 1986; Turner, Hogg, Oakes, Reicher, \& Wetherell, 1987), both drawn from the well established literature on intergroup relations.

The former, the information/decision making perspective, proposes that differences within a group's composition should be positively related to group performance, through greater variability in skills, abilities, and perspectives. Ultimately, this is thought to extend the knowledge base from which the group members can make decisions, and likewise will stimulate members to consider other options, thereby resulting in more thoughtful processing of problems and the impetus to generate more novel ideas (Cox \& Blake, 1991).

Alternatively, the social categorization perspective posits that workgroup diversity can be detrimental to satisfaction and performance. Specifically, proponents of this approach (e.g.
Riordan \& Shore, 1997; Tsui et al., 1992) argue that group members will use similarities and differences between themselves and fellow members to form salient characteristics for comparison. In turn, they will use these attributes as a basis for categorizing the self and others into in-groups and out-groups based on the relevant prototype (Tajfel \& Turner, 1986; Turner et al., 1987; for further explanation see Hogg \& Terry, 2000). The use of such social comparisons strategies results in poor group relations, meaning group members may defend themselves against these group differences by denigrating other group members, expressing ethnocentric attitudes toward dissimilar others (out-group bias), or evaluating their own group as superior (in-group bias) (Ensari \& Miller, this issue).

Studies conducted using social categorization as a theoretical framework have tended to classify attributes into those that are easily used to categorize individuals into groups (e.g. readily-detectable traits such as gender and raceethnicity) compared to those attributes that are less visible and less salient characteristics of individuals. In contrast, research informed by the information/decision-making approach has largely classified attributes into those clusters that are job or task-related (and hence confer real differences in knowledge, skills and abilities) and those that are, at least hypothetically, unrelated to the group performance. It appears, therefore, that the effect of diversity in characteristics that are subject to social categorization processes potentially will lead to reduced cohesion within the group, while the influence of diversity in attributes that are perceived as being task-orientated potentially will lead to increased group performance.

Despite considerable research efforts to classify diversity traits, there is surprisingly little empirical support for so doing. For example, in a recent meta-analysis of 24 studies, Webber and Donahue (2001) examined the impact of job-related diversity on work group cohesion and performance, and found that there was no relationship between highly job-related attributes and work group performance, nor between less job-related attributes and group 
cohesion. In fact, Webber and Donahue (2001) found no relationships between these variables, leading them to conclude that the link between highly job-related and less job-related diversity with cohesion and performance has been overstated, a theme echoed by the earlier work of Bower, Pharmer, and Salas (2000). While at first these findings appear counterintuitive, it is possible to argue that there are several explanations that could account for the apparent emerging patterns.

One approach to exploring the relationship between diversity management and performance, or more generally conditions that might maximize positive outcomes of diversity, has been to test for potential 'third variable explanations'-or moderators of diversity's effects. By moderators, we mean variables that according to Baron and Kenny (1986) act to partition 'a focal independent variable into subgroups that establish its domains of maximal effectiveness in regard to a given dependent variable' (p. 1173). In recent years more than a dozen different moderators have been explored. For instance, temporal factors and the organizational context have been suggested as potential variables moderating the effects of diversity such that it may decrease over time (e.g. Watson, Kumar, \& Michaelsen, 1993), or increase within organizations where diversity is valued. Other variables including task-related factors, such as the type of task (e.g. production vs. cognitive), the difficulty of the task (Bower et al., 2000), or the type of work team/the tasks performed by each member (e.g. production, project, management, and parallel; Stewart, 2006), have each been factors partially accounting for variance in findings, and thus viewed as moderating the influence of diversity within workgroups. Additionally, Hutchison, Jetten, Christian, \& Haycraft (in press) have demonstrated that induced social perceptions can also serve as a moderating type variable.

In a similar vein, researchers have also argued that a considerable amount of the literature fails to take into account interactions between and among diversity attributes. Indeed, in a review of applied diversity research, Jackson et al. (2003) noted that less than $5 \%$ of the studies they considered had examined the data for moderating or mediating effects, but instead examined main effects only. There were some definite exceptions to this general finding, however, such as a study by Jehn et al. (1999), where the investigators found that when social category diversity was high (as measured by sex and age), informational diversity (education and function) was negatively related to group efficiency, but not when social category diversity was low. Such laudable exceptions to studies that solely analyze main effects only serve to emphasize the key point that to gain a more comprehensive understanding of the impact of diversity attributes, researchers must move beyond examining variables as components in isolation from each other.

\section{The use of 'hybrid models'}

The idea that moderating and mediating factors-such as task specificity, strength of identification, and so on-need to be taken into account represents a significant move forward, away from the traditional notion that job related diversity behaves in the same way as social category diversity. It renews an emphasis on understanding the complexities of diversity, while also implying that greater theory integration is required. This also has increased interest in applying more 'hybrid models' that are drawn from both the information decision making and social categorization perspectives (see Van Knippenberg et al., 2004). Such applications of theory aim to pinpoint more precisely when positive and negative diversity outcomes occur. For example, Ensari and Miller (this issue) suggest that factors such as intergroup bias stemming from social categorization processes can disrupt the group's communication effectiveness, which in turn will reduce performance. They, therefore, posit that the personalization paradigm overcomes this by using a number of components including self-disclosure and empathy as ways to reduce the negative effects of discrimination resulting from a diverse working environment. In sum, we can observe definite advances in 
conceptual sophistication, but arguably there is still not a dominate paradigm that unites the literature.

\section{The Special Issue}

Despite the considerable amount of research that has been conducted exploring diversity over the past 20 years, there are many continuing issues of debate. As such, the papers in this Special Issue are divided into basic and applied contributions, reflecting the advances in both the use of sampling and/or methodological implementations leading to intervention development, or to the development of theory, per se (i.e. examining moderators, increasing predictive utility, and retheorizing). Picking up on the latter point, in their comprehensive review of the literature Williams and O'Reilly (1998) stated that the 'theory most commonly used by demography researchers ... is predicated upon the logic of social categorization theory (Tajfel, 1981; Turner, 1987) and social identification (sic) theory (Hogg \& Abrams, 1988; Turner, 1982)'. Clearly, if diversity management initiatives are to be implemented successfully, a greater knowledge and understanding of the basic and complex processes resulting from their implementation is required. Although the real utility of theory can only be tested in applied settings, this must depend on the development of solid testable theories with strong predictive value. Accordingly, the bulk of the articles in this edition present a blend of basic and applied research. The following section provides a brief overview of the articles.

As previously stated, one of the issues facing diversity research has been that of defining diversity, and exploring how different types of diversity such as surface-level and deep-level diversity influence group decision-making. There are two articles presented in this edition that explore types of diversity and their influence on decision-making and conflict resolution. First, Phillips and her colleagues report on the influence of surface-level diversity (based on race) and deep-level similarities on group processing and individual team members' attraction to others. Hobman and Bordia, likewise, report on the role of team identification (in similar and dissimilar groups) and its influence on conflict resolution strategies on group performance. Among the challenges that this latter study tries to address is that of the longitudinal/temporal effects of diversity within groups.

Next, Hewstone et al. examine the effects of group proportions-in particular, the ratios of men versus women within the academic context-on perceptions of the group. Such perceptions help to target questions about group cohesion, as the out-group homogeneity effect discussed in this article directly addresses issues about organizational 'entitavity'-or organizational cohesion-which van Kippenberg et al. (2002) would argue is essential to identification with an organization and positive work relations.

The fourth article by von Hippel deals with the issue of intergroup attitudes expressed by temporary and permanent employees on both implicit and explicit measures, using social identity theory as a framework. A key point raised in social identity theory is that low-status groups with permeable boundaries are expected to show an out-group bias in favor of permanent employees (the higher status group). Given the complexities involved in sampling and administering such a study, relatively little work has looked at this issue within workgroups. The von Hippel article uses a lexical task and other measures to assess both levels of attitudes and reports on differences in perceptions between low and high status groups.

Similarly, Boen et al. examine the moderating role of perceived status within an organizational context. However, in this investigation, the researchers probe employees' identification scores following a merger between two corrugated board producing companies. They argue that post-merger status is most likely to be an important diversity variable-but only for employees who identified strongly with the premerger organizations.

The sixth contribution, by Luijters, van der Zee, and Otten, reports on an application of diversity research that examines the possibility 
that 'diversity' is entwined in multiple identifications when considering this issue within the context of minority workers populations. One of the strongest contributions of this article is the application of diversity research to migrant workers: whereas much research using theory driven models has been conducted using student populations, considerably less has been carried out on hard-to-access minority groups. Also, the work seeks to incorporate social/ migrant adjustment models of acculturation to explain the influence of work, culture, and acculturation strategies on conflict and diversity-related stress perceptions.

In the following article, Rink and Ellemers examine the moderating role of work goal expectancies on group performance. They demonstrate when work goal expectancies are confirmed, people feel relatively little disappointment and are happy to remain committed to carry out further tasks. However, violations of expectancies result in poor collaborative relationships. On this basis, Rink and Ellemers argue that the effects can be best understood in terms of expectancy violation and congruence theory, thus extending the range of diversity research.

Finally, Ensari and Miller explore the possibilities of applying theory-based interventions as a means for increasing the predictive utility of diversity research. At the core of the argument presented in this article is the notion that diversity studies commonly suffer from the absence of conceptualizing diversity as part of a process (social perception) of higher order prejudice that leads to discrimination in the workplace. They suggest considering a number of components, including self-other comparison, selfdisclosure, and empathy, as ways to reduce the negative effects of such social exclusion.

In conclusion, the work reported in this Special Issue extends theory and research, integrates current and emerging knowledge, and highlights new directions for future research. From applications through to further avenues for new research, the eight articles presented in this issue address important issues linked to both the theory and practice of researching diversity.

\section{References}

Ancona, D. G., \& Caldwell, D. F. (1992). Demography and design: Predictors of new product team performance. Organization Science, 3, 321-341.

Bantel, K. A. (1994). Strategic planning openness: The role of top team demography. Group $\mathcal{E}$ Organization Management, 19, 406-424.

Baron, R. M., \& Kenny, D. A. (1986). The moderator-mediator variable distinction in social psychological research: Conceptual, strategic, and statistical considerations. Journal of Personality and Social Psychology, 51, 1173-1182.

Bower, C. A., Pharmer, J. A., \& Salas, E. (2000). When member homogeneity is needed in work teams-A meta-analysis. Small Group Research, 31, 305-327.

Cox, T., \& Blake, S. (1991). Managing cultural diversity: Implications for organizational competitiveness. Academy of Management Executive, $5,45-55$.

Ely, R. J., \& Thomas, D. A. (2001). Cultural diversity at work: The moderating effects of work group perspectives on diversity. Administrative Science Quarterly, 46, 229-273.

Fullerton, F. N., \& Toossi, M. (2001). Labor force projections to 2010: Steady growth and changing composition. Monthly Labor Rev, 124, 21-38.

Harrison, D. A., Price, K. H., \& Bell, M. P. (1998). Beyond relational demography: Time and the effects of surface- and deep-level diversity on work group cohesion. Academy of Management Journal, 41, 96-107.

Hickman, G. R., \& Creighton-Zollar, A. (1998). Diverse self-directed work teams: Developing strategic initiatives for 21st century organizations. Public Personnel Management, 27, 187-200.

Hogg, M. A., \& Abrams, D. (1988). Social identifications: A social psychology of intergroup relations and group processes. London: Routledge.

Hogg , M. A., \& Terry, D. J. (2000). Social identity and self-categorization processes in organizational contexts. Academy of Management Review, 25, 121-140.

Hutchison, P., Jetten, J., Christian, J., \& Haycraft, E. (in press). Protecting threatened identity: Sticking with the group by emphasizing ingroup heterogeneity. Personality and Social Psychology Bulletin.

Jackson, S. E. (1992). Consequences of group composition for the interpersonal dynamics of strategic issue processing. In P. Shrivastava, A. Huff, \& J. Dutton (Eds.), Advances in Strategic Management (Vol. 8, pp. 345-382). Greenwich, CT: JAI. 
Jackson, S. E., Joshi, A., \& Erhardt, N. H. (2003). Recent research on team and organizational diversity: SWOT analysis and implications. Journal of Management, 29, 801-830.

Jackson, S. E., May, K. E., \& Whitney, K. (1995). Under the dynamics of diversity in decision-making teams. In R. A. Guzzo \& E. Salas (Eds.), Team effectiveness and decision making in organizations (pp. 204-261). San Francisco: Jossey-Bass.

Jehn, K. A., Northcraft, G. B., \& Neale, M. A. (1999). Why differences make a difference: A field study of diversity, conflict, and performance in workgroups. Administrative Science Quarterly, 44, 741-763.

Kanter, R. M. (1977). Men and women of the corporation. New York: Basics Books.

Maznevski, M. L. (1994). Understanding our differences-Performance in decision-making groups with diverse members. Human Relations, 47, 521-552.

McLeod, P., Lobel, S., \& Cox, T. (1996). Ethnic diversity and creativity in small groups. Small Group Research, 27, 248-64.

Milliken, F. J., \& Martins, L. L. (1996). Searching for common threads: Understanding the multiple effects of diversity in organizational groups. Academy of Management Review, 21, 402-433.

Pelled, L. H. (1996). Demographic diversity, conflict, and work group outcomes: An intervening process theory. Organization Science, 7, 615-631.

Pelled, L. H., Eisenhardt, K. M., \& Xin, K. R. (1999). Exploring the black box: An analysis of work group diversity, conflict, and performance. Administrative Science Quarterly, 44, 1-28.

Riordan, C., \& Shore, C. (1997). Demographic diversity and employee attitudes: An empirical examination of relational demography within work units. Journal of Applied Psychology, 82, 342-358.

Simons, T., Pelled, L. H., \& Smith, K. A. (1999). Making use of difference: Diversity, debate, and decision comprehensiveness in top management teams. Academy of Management Journal, 42, 662-673.

Smith, K. G., Smith, K. A., Olian, J. D., Sims, H. P., O'Bannon, D. P., \& Scully, J. A. (1994). Top management team demography and process: The role of social integration and communication. Administrative Science Quarterly, 39, 3, 412-438.

Stewart, G. L. (2006). A meta-analytic review of relationships between team design features and team performance. Journal of Management, 32, 29-54.
Tajfel, H. (1981) Human groups and social categories. Cambridge, UK: Cambridge University Press.

Tajfel, H., \& Turner, J. C. (1986). The social identity theory of intergroup behavior. In S. Worchel \& W. G. Austin (Eds.), The psychology of intergroup relations (pp. 7-24). Chicago: Nelson-Hall.

Tsui, A. S., Egan, T. D., \& O’Reilly, C. A., III (1992). Being different: Relational demography and organizational attachment. Administrative Science Quarterly, 37, 549-579.

Turner, J. C. (1982). Towards a cognitive redefinition of the social group. In H. Tajfel (Ed.), Social identity and intergroup relations (pp. 15-40). Cambridge, UK: Cambridge University Press. Turner, J. C. (1987). A self-categorization theory. In J. C. Turner, M. A. Hogg, P. J. Oakes, S. D. Reicher, \& M. Wetherell (Eds.), Rediscovering the social group: A self-categorization theory (pp. 117-141). Oxford, UK: Blackwell.

Turner, J. C., Hogg, M. A., Oakes, P. J., Reicher, S., \& Wetherell, M. S. (1987). Rediscovering the social group: A self-categorization theory. Oxford, UK: Blackwell.

Van Knippenberg, D., De Dreu, C. K. W., \& Homan, A. C. (2004). Work group diversity and group performance: An integrative model and research agenda. Journal of Applied Psychology, 98, 1008-1022.

Watson, W., Kumar, K., \& Michaelsen, L. (1993). Cultural diversity's impact on interaction process and performance: Comparing homogeneous and diverse task groups. Academy of Management Journal, 36, 590-602.

Webber, S. S., \& Donahue, L. M. (2001). Impact of highly and less job-related diversity on work group cohesion and performance: A meta-analysis.

Journal of Management, 27, 141-162.

Wiersema, M. F., \& Bantel, K. A. (1992). Top management team demography and corporate strategic change. Academy of Management Journal, 35, 91-121.

Williams, K. Y., \& O’Reilly, C. A., III. (1998). Demography and diversity in organizations: A review of 40 years of research. In B. M. Staw \& L. L. Cummings (Eds.), Research in organizational behavior (Vol. 20, pp. 77-140). Greenwich, CT: JAI Press.

\section{Biographical notes}

JULIE CHRISTIAN is a lecturer at the University of Birmingham. She completed her PhD thesis on social attitude formation at the University of Wales in 1998. Julie has an established track record in researching social attitudes, social identity and 
applied social issues (private and social housing), publishing over 30 scientific papers and government reports. As a direct extension of this work, she holds board positions with several UK charities and companies.

LYMAN W. PORTER is Professor of Management in the Graduate School of Management at the University of California, Irvine, and was formerly Dean of that School. Professor Porter is a past president of The Academy of Management. He has also served as President of the Society of
Industrial-Organizational Psychology (SIOP). Professor Porter's major fields of interest are organizational psychology, management, and management education. He is the author or co-author of 11 books and over 90 articles in these fields.

GRAHAM MOFFITT'S (BA (Hons), University of Queensland) research interests include intergroup relations, social identity and self-categorization theory, and political psychology. 